\title{
Bioética e pesquisa em saúde mental
}

\author{
Bioethics and research into mental health
}

Marlene Braz ${ }^{1}$

Fermin Roland Schramm ${ }^{1}$

${ }^{1}$ Escola Nacional de Saúde Pública Sergio Arouca, Fundação Oswaldo Cruz. Rua Leopoldo Bulhões, 1.480/914, Manguinhos. 21041-210 Rio de Janeiro RJ.braz@iff.fiocruz.br
Abstract This article discusses research in the field of mental health, examining the ethical issues involved and the use of Informed Consent. In order to achieve these objectives two main approaches were used: (1) a brief history of the different treatments and research with patients with mental illness or disability; (2) theoretical and conceptual analysis of the main problems concerning the mental health field, namely the notion of vulnerability, responsibility and autonomy and the use of placebo control groups. Two main questions prompted the reflection on whether the patient with a mental disorder can sign an Informed Consent, and whether the use of a placebo is acceptable. The existence of antagonistic and contradictory positions indicates that mental health research is hampered by biases that are difficult to overcome. Ethical investigation that may contribute to the healing of mental disorders should not however be overlooked merely because of the difficulties involved in its implementation. It must be borne in mind that changes occurring in the context of Psychiatric Reform in Brazil are gradually altering archaic concepts about what constitutes mental illness and how this group should be understood and treated.

Keywords Bioethics, Research on vulnerable subjects, Mental disorders, Mental illness, Use of a placebo, Autonomy
Resumo Este artigo discute as pesquisas no campo da saúde mental, analisando questões éticas envolvidas e uso do Termo de Consentimento Livre e Esclarecido. Para alcançar os objetivos, foram seguidos dois percursos principais: (1) breve histórico dos diferentes tratamentos e pesquisas com pacientes com transtornos mentais ou deficiência; (2) análise teórico-conceitual dos principais problemas relativos ao campo da saúde mental, quais sejam a noção de vulnerabilidade, competência e autonomia e o uso de grupos-controle com placebo. Duas perguntas principais moveram a reflexão: se o paciente com transtornos mentais pode assinar o Termo de Consentimento Livre e Esclarecido e se uso de placebo é aceitável. Concluiu-se pela existência de posições antagônicas e contraditórias, indicando que a pesquisa em saúde mental está minada por vieses de difícil solução. Não se pode, entretanto, deixar de lado, pelas dificuldades, as investigações éticas que contribuam para a cura dos transtornos mentais, devendo se atentar para as mudanças que vêm ocorrendo em razão da Reforma Psiquiátrica no Brasil, que tem mudado concepções arcaicas acerca do que seja doença mental e de como esse grupo deve ser compreendido e tratado.

Palavras-chave Bioética, Pesquisa em vulneráveis, Transtornos mentais, Doença mental, Uso de placebo, Autonomia 


\section{Introdução}

$\mathrm{O}$ incremento de pesquisas envolvendo seres humanos no mundo, conjuntamente com os abusos de profissionais de saúde contra populações vulneráveis, levou muitos governos a criarem Comissões Nacionais de Ética em Pesquisa com a finalidade de proteger as pessoas envolvidas em pesquisas.

No Brasil, foi promulgada a Resolução CNS 196/96 e foram criadas a Comissão Nacional de Ética em Pesquisa (Conep) e os Comitês de Ética em Pesquisa (CEP) nos centros de pesquisas e universidades. Tais dispositivos têm a função principal de proteger as pessoas em situação de vulnerabilidade contra sua exploração por parte de investigadores inescrupulosos.

A bioética, que já completou quarenta anos, tem-se debruçado sobre as questões envolvidas com a vulnerabilidade e a possibilidade de exploração de populações suscetíveis, seja por motivos socioeconômicos culturais, seja por problemas de saúde física ou mental.

Este artigo se propõe a discutir as pesquisas no campo da saúde mental, analisando as questões éticas envolvidas, destacando as de vulnerabilidade, de autonomia e de competência moral dos pacientes com transtornos mentais e do uso do Termo de Consentimento Livre e Esclarecido (TCLE).

Para alcançar tais objetivos, seguiram-se dois percursos principais: (1) breve histórico dos diferentes tratamentos e pesquisas com pacientes com transtornos mentais ou deficiência; (2) análise teórico-conceitual dos principais problemas relativos ao campo da saúde mental, como a noção de vulnerabilidade, competência e autonomia e o uso de grupos-controle com placebo. As questões relevantes do texto são: o paciente com transtornos mentais pode assinar o TCLE? O uso de placebo é aceitável?

\section{História insensata do tratamento dispensado aos loucos}

De acordo com Foucault, antes de a loucura ser dominada, os loucos viviam como errantes, embarcados na Narrenschiff ou Nave dos Loucos. Eram escorraçados para fora dos muros das cidades ou deixados vagando pelos campos ou entregues a mercadores ou peregrinos. Essa atitude era um vestígio da época inquisitorial, pois lhes era negado entrar numa igreja por presumidamente serem possuídos pelo demônio. Ao mesmo tempo, a loucura exercia fascínio, pois pensava-se que o saber tinha que ser extraído das entranhas da terra e, no imaginário da época, o louco o possuía por inteiro, mas de forma invisível, ao contrário do sábio, que só o detinha de forma fragmentada. Por isso, o saber dos loucos era proibido ${ }^{1}$.

No século XVI, a concepção da loucura passa a fazer sentido dentro do próprio campo da razão, que se deixa penetrar por ela para melhor se defender dela ${ }^{1}$. É por essa mudança que o louco será, a partir do século XVII, encarcerado em casas de internação e de loucos, o hospital. A prática de internamento, no entanto, se estende também aos miseráveis, libertinos, vagabundos e bandidos. A loucura, fazendo parte dessa visão heterogênea, será classificada ora na categoria da beneficência, ora na repressão. Todo interno é colocado no campo dessa valoração ética - e muito antes de ser objeto de conhecimento ou piedade, ele é tratado como sujeito moral. Tais casas desaparecem no século XIX, mas não para os loucos, pois estes não conseguiam - por sua pretensa incapacidade para o trabalho - permanecer dentro das fronteiras da nova ordem burguesa. A loucura reinará sozinha nessas casas, encarcerada e silenciada. Entretanto, o convívio com libertinos, criminosos e doentes venéreos provocou uma espécie de assimilação obscura; e a loucura estabeleceu com as culpas morais e sociais um parentesco que não está talvez prestes a morrer ${ }^{2}$.

Essa concepção da loucura implicou tratamentos desumanos, pois lhes eram prescritos disciplina, ameaças, grilhões e golpes tanto quanto o tratamento médico ${ }^{3}$, além de purgantes, vomitórios e sangrias. O médico era figura ausente das casas, mantendo-se afastado dos doentes mentais, deixando-os nos calabouços e nas correntes.

A partir do século XVII, crescem os estudos do cérebro, já considerado a sede do espírito e, consequentemente, da loucura. Nasce a neurofisiologia e, no século XVIII, a neuropatologia. Começam a ser formuladas as bases de uma psiquiatria sem psicologia ${ }^{3}$. Nesse mesmo século, Stahl examinou as doenças mentais, discutindo o abismo existente entre o corpo e o espírito, vendo nisto um prejuízo do conhecimento das doenças e, em particular, da doença mental. Valorizava a compreensão da alma e acreditava que as emoções poderiam influir na recuperação de uma doença somática ${ }^{3}$.

No século XVIII, acontece a abolição das correntes e a preocupação passa a ser investigar as enfermidades mentais, já não mais vistas como possessões demoníacas. Cresce, também, a aten- 
ção do médico para a classificação dessas doenças. Tais classificações, entretanto, não se atinham à própria loucura, nelas intervindo julgamento moral e atribuição de causas orgânicas. ${ }^{1}$ Continuavam a existir casas de loucos, sem a preocupação de tratá-los. Foi Philippe Pinel que assegurou um lugar à psiquiatria como especialidade médica, observando que os loucos, além de não serem delinquentes dignos de castigo, são pessoas enfermas cujo estado miserável merece toda a consideração que se deve à humanidade doente e que há que tratar de recuperar sua razão com métodos mais simples ${ }^{3}$. Pinel introduz a anamnese psiquiátrica, reorganiza o hospital e acrescenta ao tratamento físico o tratamento moral, entendido como uma reeducação do louco: respeito às normas e não aceitação de condutas inconvenientes, assinalando que a permanência demorada do médico em contato com os doentes melhora seu conhecimento sobre os sintomas e sobre a evolução da loucura ${ }^{3}$.

O tratamento moral não vicejou e os cuidados preconizados não foram seguidos por todos. Continuaram a predominar a coerção para o controle das condutas, a ordem e a disciplina do manicômio e os terríveis tratamentos.

No século XIX, o debate será sobre a organogênese e a psicogênese das doenças mentais, a descoberta da causa da paralisia cerebral e da histeria sem substrato anatômico ou fisiológi$\mathrm{co}^{3}$. Na luta entre os organicistas e os psicólogos, saem ganhando os primeiros, segundo os quais o diagnóstico deve basear-se em causas fisiológicas, e o médico deve olhar o corpo e nele buscar a origem da doença. Na Alemanha, nessa época, Kraepelin investe na sistematização psiquiátrica, tornando a psiquiatria uma especialidade da medicina ${ }^{3}$. Kraepelin dá um ordenamento ao caos classificatório das doenças mentais, interessando-se por saber como o paciente pensa. O estudo sistemático e extenso o levou à conclusão da existência de dois tipos de doenças mentais: a demência precoce e a psicose maníaco-depressiva. Mais tarde ele incluiu a parafrenia. Também dividiu as psicoses em endógenas e exógenas classificação que permanece até hoje.

No final do século XIX, ocorre o que Zilboorg e Henri ${ }^{3}$ denominaram Segunda Revolução Psiquiátrica, que trará para a psiquiatria a psicologia. Freud será o responsável por isto, através de seu discípulo Bleuler, na Alemanha. Bleuler reviu as ideias de Kraepelin e lançou as bases para uma psiquiatria dinâmica, introduzindo o termo "esquizofrenia", que implicava ver a doença como um conjunto de reações psíquicas e não, apenas, como uma enfermidade orgânica. Descreveu também o pensamento autístico baseado em algumas observações de Freud sobre o narcisismo ${ }^{3}$.

Todos esses fatos não mudaram o objetivo da descoberta de medicamentos que sustentassem a teoria sobre a origem puramente orgânica da doença mental. Apesar do avanço no entendimento das patologias mentais, medidas cruentas continuaram sendo empregadas: duchas e banhos frios, chicotadas, máquinas giratórias e sangrias. Tais condutas se estendem até a descoberta de medicamentos, que foram substituindo tratamentos rudimentares como lobotomia, eletrochoque, choque cardiazólico, insulinoterapia, malarioterapia e contenção física.

Em 1952, é clinicamente introduzida na França, através do Laborit, o primeiro medicamento antipsicótico: clorpromazina ${ }^{4}$. Este medicamento e outros que o sucederam substituíram aos poucos as terapias existentes e o uso de drogas sedativas e hipnóticas. Novos medicamentos foram desenvolvidos e hoje existem mais de $400^{4}$.

Aos poucos, foi-se reconhecendo o papel dos fatores biológicos, psicológicos, sociais e culturais na gênese e na evolução das doenças mentais. Entretanto, concepções arcaicas da relação entre doença, culpa e pecado permanecem até os dias atuais, colaborando, significativamente, para a estigmatização do doente mental.

\section{Vulnerabilidades, competência e autonomia nas pesquisas com pacientes com transtorno mental}

\section{Sobre vulnerabilidade}

$\mathrm{Na}$ psiquiatria, não raramente, se mesclam ciência e ideologia, conhecimento e preconceito, aspirações libertárias e medidas repressivas ${ }^{5}$. Diante de tal constatação, como pensar as noções fundamentais relacionadas ao paciente com transtornos mentais? Eles teriam a capacidade para exercer uma autonomia plena?

Começando pela vulnerabilidade, em vários estudos sobre o assunto ${ }^{6-11}$ se fala de uma gradação do menos ao mais ou de diferentes vulnerabilidades $^{9-12}$. Em primeiro lugar estariam as todas as pessoas que, pelo fato de estarem vivas, podem ser vulneradas ou feridas ${ }^{11}$. Em segundo lugar estariam os suscetíveis, aqueles em situação de maior risco de serem atingidos ${ }^{12}$. Em terceiro lugar, os propriamente vulnerados, os que já foram de fato feridos ${ }^{12}$. Por último, os desmedrados, os que não tiveram a oportunidade de 
desenvolver suas potencialidades ${ }^{9-11}$, como é o caso dos indivíduos com transtorno mental e os deficientes, que jamais puderam se defender de abusos, ficando aquém das potencialidades para assumir suas vidas.

Com relação à participação dos doentes mentais em pesquisas, o Código de Nuremberg de $1950^{13}$ já não lhes permitia, argumentando que não poderiam dar livremente seu consentimento, o que é considerado condição necessária. Esse dispositivo incluía loucos, deficientes e crianças, entre outros vulneráveis.

1 O consentimento voluntário do ser humano é absolutamente essencial. Isso significa que as pessoas que serão submetidas ao experimento devem ser legalmente capazes de dar consentimento ${ }^{9}$.

A Declaração de Helsinki ${ }^{14}$ de 1964 abriu as portas para pesquisas com esses grupos, conforme exposto no Item II.1:

1 - [...] Sendo possivel, e de acordo com a psicologia do paciente, o médico deve obter o livre consentimento do mesmo, depois de lhe ter sido dada uma explicação completa. Em caso de incapacidade legal, o consentimento deve ser obtido do responsável legal; em caso de incapacidade física, a autorização do responsável legal substitui a do paciente.

Este item foi modificado na Declaração de $1996^{15}$ e passou a ter a seguinte redação:

11 No caso de incapacidade legal, o consentimento informado deve ser dado pelo responsável, estabelecido segundo a legislação do país.

O que se pode constatar, comparando o Código e a Declaração, é que houve uma piora na proteção da população aqui em exame, pois não se mencionam as particularidades dos pacientes com transtorno mental. Pois a Declaração não permite identificar quem é esse paciente, em suas especificidades, nem o que é eticamente correto fazer com ele, subsumindo de fato a questão ética à mera questão legal. Em suma, fala-se genericamente em incapacidade legal e que o pesquisador deve seguir as leis de cada país. Ora, sabe-se que em países pobres ou que ainda não possuem um órgão que regulamente as pesquisas em seu território as normas são frágeis. Ao mesmo tempo, institui-se um responsável para as pessoas do grupo aqui citado, sem especificar quem seria.

A principal consequência da falta de clareza foram os abusos, como foi o resultado catastrófico do estudo clínico, duplo cego com placebo, realizado em 1996 na África do Sul e em outros países em desenvolvimento ${ }^{16}$. Essa pesquisa foi acusada de abusiva, por envolver uma tentativa de capitalizar resultados à custa da exploração de vulneráveis. Os pesquisadores contra-argumentaram que o trabalho deles só poderia ser realizado de maneira aceitável entre as mulheres pobres, que tiveram poucas escolhas em relação ao tratamento que lhes seria agraciado. Significou reconhecer que a vulnerabilidade delas as converteu em alvos preferenciais da pesquisa ${ }^{16}$.

O citado estudo provocou uma mudança na Declaração de Helsinki em $2000^{17}$, que confirmou restrições ao uso de placebo (item 29) e preconizou seu uso para o grupo-controle quando não houvesse outro tratamento disponível. Mas a mudança, eticamente significativa, se deu no parágrafo 30, que garantiu o acesso aos doentes participantes dos melhores métodos profiláticos, diagnósticos e terapêuticos identificados pelo estudo.

A mesma Declaração foi revista em $2008^{18}$ : os artigos 19, 29 e 30 mudaram de numeração e tiveram nova redação, diminuindo de fato a proteção e a defesa dos interesses dos grupos vulneráveis ${ }^{19}$. Por exemplo: no Item 14 , foi incluída a seguinte frase: $O$ protocolo deve descrever acordos para os sujeitos de investigação ter acesso pós-estudo às intervenções identificadas como benéficas ou acesso a outro cuidado ou benefício apropriado ${ }^{19}$. Este enunciado retirou a obrigação de beneficiar os participantes com as novas descobertas, testadas neles, deixando isso para os acordos. Ademais, na segunda parte do artigo 32, o uso do placebo passou a ser justificável quando por razões científicas e metodológicas obrigatórias o uso do placebo for necessário para determinar a eficácia ou segurança de uma intervenção e os pacientes que recebem placebo ou nenhum tratamento não estarão sujeitos a nenhum risco de sofrer dano sério ou irreversível ${ }^{19}$. Por último, no artigo 33 , há flexibilização nas exigências de se obterem os melhores tratamentos, pois os sujeitos da pesquisa podem ter acesso a intervenções identificadas como benéficas no estudo ou outro cuidado ou benefício apropriado ${ }^{19}$.

Apesar das disposições internacionais em vigor e suas revisões, a da recomendação de não se utilizar placebo sempre foi uma prática costumeira na psiquiatria. Num livro escrito por Fro$\mathrm{ta}^{4}$, no qual o autor disserta sobre as descobertas das drogas e apresenta uma ampla revisão de artigos sobre como foram feitas as pesquisas, fica claro que o método consagrado é o uso de placebo. Porém, é bom dizer que mesmo com as mudanças na Declaração de Helsinki, a RS 196/ 96 não foi alterada. No Brasil continua proibido o uso de placebo, o que vem causando grande indignação no seio da psiquiatria. 


\section{Competência e incapacidade}

A prática do uso de placebo em populações de pacientes com transtorno mental tem uma série de implicações, principalmente quanto à autonomia e à competência dos sujeitos-objeto da pesquisa ${ }^{20}$.

A autonomia é definida como capacidade de a pessoa humana ser agente moral e ter autodeterminação, de decidir livremente sobre sua vida e arcar com as consequências das decisões, desde que isso não afete terceiros ${ }^{21}$. O respeito deste importante princípio da bioética implica respeitar a vontade, as crenças e os valores do paciente, não instrumentalizando a sua vontade elou o seu $\operatorname{ser}^{22}$.

Nesse sentido, os movimentos dos direitos de pessoas portadoras de disabilidades (Disability Rights ${ }^{23}$, presentes em vários países, assumem que o maior valor a se garantir é a autonomia das pessoas, o que implica profundas mudanças nas políticas públicas e nos serviços de saúde, o que vem ao encontro das propostas da Reforma Psiquiátrica, no Brasil, que consideram essa condição de cidadania sem preconceito, fundamental para que os usuários do sistema psiquiátrico possam apresentar reivindicações sobre como, de que jeito querem ser tratados e em que sociedade pretendem viver ${ }^{24}$.

No caso das pesquisas com portadores de transtornos mentais, respeitar a autonomia implica, para o pesquisador, respeitar e - se necessário - ajudar o paciente a superar sua dependência, expressar os seus valores e preferências, e envolvê-lo na decisão de se submeter ou não a uma investigação. Nesse sentido, o respeito à autonomia tem como corolário o TCLE, que pode ser visto como "instrumento da beneficência", em que a pessoa toma livremente a sua decisão, devidamente esclarecida acerca dos procedimentos, consciente dos riscos, benefícios e consequências ${ }^{22}$. No entanto, existem circunstâncias que limitam ou impedem a obtenção do consentimento informado, entre elas a incapacidade de adultos com diminuição sensorial ou da consciência, nas patologias neurológicas ou psiquiátricas severas ${ }^{22}$.

Para outros grupos como o de crianças e adolescentes, a compreensão sobre o consentimento já evoluiu, como disposto no novo Código de Ética Médica de 201025. Mas isso não ocorreu em relação aos pacientes com transtornos mentais, olhados como indivíduos sem autonomia, incapacitados judicialmente e curatelados, pela família ou pelo Estado. O estigma do doente mental como violento, podendo atentar contra a pró- pria vida ou a dos outros, é considerado motivo que justifica intervir nas ações destes indivíduos para protegê-los dos resultados perigosos das suas escolhas ou ações ${ }^{26}$. Mas pesquisas apontam que percentualmente, em relação à população em geral, o doente mental não é mais violento ${ }^{27,28}$.

Se não há autonomia, espera-se que os pesquisadores respeitem o princípio da beneficência ou não maleficência. Entretanto, observa-se muito paternalismo nessas relações. Mesmo quando se preconiza que o doente mental, fora das crises, possa ter autonomia e traçar o que se denomina "testamento vital" ou "diretrizes antecipadas" 29 , em relação ao que deseja que seja feito em relação a sua pessoa em tratamentos ou pesquisa, isso é completamente ignorado sob o pressuposto de sua incapacidade.

De acordo com as normas éticas de pesquisa em relação às investigações clínicas ou qualitativas, seria injustificável, em qualquer hipótese, não pedir o consentimento. Exceção se faz aos pacientes crônicos, institucionalizados e sem família que os ampare e consinta na pesquisa. Entretanto, nesses casos, RS 196/96 estabelece ${ }^{30}$ :

IV.3 Nos casos em que haja qualquer restrição à liberdade ou ao esclarecimento necessários para o adequado consentimento, deve-se ainda observar:

a) em pesquisas envolvendo [...] sujeitos em situação de substancial diminuição em suas capacidades de consentimento, deverá haver justificação clara da escolha dos sujeitos da pesquisa, [...] e cumprir as exigências do consentimento livre e esclarecido através dos representantes legais dos referidos sujeitos, sem suspensão do direito de informação do indivíduo, no limite de sua capacidade.

De fato, autonomia tem a ver com poder, de acordo com o movimento de empowerment iniciado nos Estados Unidos no século XX, principalmente no fim da década de 1980: os grupos marginalizados e discriminados na sociedade sofrem de uma falta de poder que os impede de lutar pelos seus direitos e usufruir de benefícios econômicos e sociais, assim como de participar nas decisões politicas que interferem nas suas vidas. Para alterar esta situação é necessário que esses grupos aumentem as suas competências e o seu poder ${ }^{31}$.

Autonomia e empoderamento são novas maneiras de perceber o doente mental, o que exige uma conduta colaborativa dos pesquisadores. Mas, para grande parte dos psiquiatras, essa posição não é sustentável, como expressa Geraldes $^{32}$, para quem a ausência de autonomia se justifica porque em psiquiatria esta questão não está resolvida. Especificamente em relação ao TCLE, o autor escreve: no caso do doente mental, não 
pode ser aplicado, embora, de praxe, a família deva ser mobilizada e incentivada a colaborar ${ }^{32}$. $\mathrm{O}$ autor entende o consentimento como um mecanismo supletivo para a autonomia não exercida pelo paciente e diz que os estudos sobre a autonomia estão nos seus primórdios e que a bioética deve aprofundá-los para expor os obstáculos e tentar equacioná-los ${ }^{32}$. Conclui: Não nos esqueçamos que a doença mental é um processo que aniquila ou debilita profundamente a individualidade e a existência dos que por ela são afetados. Se a isto adicionarmos uma pretensa autonomia, estaremos, sem dúvida, contribuindo para piorar definitivamente a qualidade de vida do doente mental ${ }^{32}$.

Outro exemplo é o de Lott ${ }^{5}$, que destaca: Pessoas incapazes envolvidas em pesquisas representam problemas um tanto diferentes [...]. Dada a redução nas habilidades cognitivas, pessoas com deficiência mental ou pessoas com demência, por exemplo, são naturalmente vulneráveis à exploração por terceiros. Por fim, Zaubler et al. ${ }^{33}$ sustentam que, historicamente, a doença mental sempre foi considerada uma patologia incapacitante, portanto o indivíduo não tem autonomia.

Entretanto, de acordo com as ferramentas bioéticas aplicada à pesquisa, o TCLE é sempre requerido, por se tratar de um requisito para a inclusão de um participante em determinada pesquisa clínica, ainda que, como observa Schüklenk, esse critério absolutamente essencial torne impossível a condução de pesquisas envolvendo a participação de doentes mentais incapazes, pois se desejarmos contribuir para melhorar a situação daqueles que sofrem de doenças que implicam sua incapacidade para manifestar o consentimento livre e esclarecido, é necessário conduzir pesquisas envolvendo tal universo ${ }^{34}$.

Em geral, o principal alvo das pesquisas são os doentes em crise ${ }^{4,35}$. É óbvio que não se nega, aqui, a importância de se testarem novas drogas que amenizem a crise ou quiçá que a revertam completamente, mas isso não exclui o consentimento ou os testes de competência cognitiva e morais fora dos momentos de crise ${ }^{36}$. Nesse sentido é que têm importância as Diretrizes Antecipadas ou o Testamento Vital já comentado.

Existem estudos que propõem testes para saber da competência dos pacientes em darem seu consentimento. Um deles é o de Roth et al..$^{37}$, que elaboraram instrumentos para aferir se o paciente consegue tomar decisões sobre seu tratamento, considerando duas condições: racionalidade da escolha e capacidade de compreender as informações.

Segundo Lopes ${ }^{38}$, diversos estudos feitos para avaliar a informação dada ao paciente para obter seu consentimento para participação em pesquisa mostram que a lembrança dessas informações, em situações diversas, é pequena ou inexistente. A autora cita um dos estudos de Irwin et al. ${ }^{39}$, destacando que na amostra examinaram-se pacientes crônicos, com diferentes diagnósticos psiquiátricos, com duração média de doença de 12,5 anos, durante a crise aguda, para os quais foi lido um termo de consentimento após as primeiras $72 \mathrm{~h} d a$ internação. Neste aparecem as informações sobre a medicação antipsicótica, ressaltando as razões para o tratamento, os benefícios e riscos, desconfortos, efeitos colaterais e informações sobre discinesia tardia. Depois foi perguntado se haviam entendido e que repetissem a informação; por fim, foram feitas perguntas específicas de acordo com questionário estruturado abrangendo questões simples, complexas e subjetivas. Foi encontrada diferença importante entre compreensão significativa na situação de lembrança geral do termo feita pelo paciente, e quando são feitas perguntas específicas, a compreensão cai de $87 \%$ para $26 \%$. Portanto, de acordo com esse estudo, o consentimento verbal de paciente psiquiátrico psicótico é altamente questionável ${ }^{38}$. Este relato leva ao seguinte questionamento: em que bases se dão essas avaliações? Durante as crises? Com pacientes crônicos?

Para se chegar a uma convergência de opiniões é necessário determinar, em primeiro lugar, se o paciente está fora da crise e se não cronificado por anos de doença e medicamentos que podem diminuir a competência cognitiva. Pacientes com déficit cognitivo permanente, de fato, não têm condições de autonomia e precisam de alguém que os represente, protegendo seus interesses. Resta, porém, um problema, que é quem decide pela incapacidade e em que condições. Há a possibilidade de um paciente ser considerado incapaz só por recusar um tratamento ${ }^{36}$.

Simplesmente não há possibilidade de se pensar autonomia quando o olhar que se lança ao paciente está eivado de ideias preconcebidas. Os loucos sofrem, ainda, uma forte carga arcaica de estigmas como: inutilidade, incapacidade, incurabilidade e defeito moral. Neste sentido, Fé $^{36}$ dá o exemplo de pacientes com transtorno do pensamento, profunda ambivalência, severo comprometimento da memória ou níveis flutuantes da consciência [que] podem ser considerados incompetentes, se tais alterações os levem a tomar decisões erráticas". Ademais, fatores circunstanciais, como a fadiga e o efeito dos medicamentos [...] podem ocasionar flutuações transitórias do estado mental e ocasionar falso resultado de incompetência, o que aponta para a conveniência de o paciente ser examinado 
várias vezes para que se tenha uma conclusão mais segura sobre seu nivel de competência ${ }^{36}$.

Sobre o principal instrumento que garante a eticidade da pesquisa envolvendo seres humanos, Hossne $^{40}$ observa que ele ter-se-ia transformado em instrumento burocrático. Outro problema é o da representação legal: o consentimento dado pelas autoridades legais constituídas; e em que pesquisas e sobre quais condições o TCLE por procuração pode ser aceito ${ }^{5}$. Outras considerações devem ser consideradas, pois no caso do TCLE por procuração pode haver impedimentos na pesquisa, como a interrupção ou troca de medicamento por dificuldade de comunicação ou por falta de habilidade do representante para reconhecer uma mudança de opinião em seus tutela$d o s^{5}$. Os mentalmente incapazes, mais suscetíveis às influências de familiares e acompanhantes, podem ficar inibidos em expressar seus desejos e interesses. Esse tipo de influência também pode vir dos pesquisadores que tendem a seduzir os pacientes a participar do estudo, levando o doente a informar a seu procurador que quer participar. Tais influências externas podem ainda emanar do próprio procurador, o que acarreta responsabilidade ainda maior para o pesquisador clínico na garantia do consentimento livre e esclarecido ${ }^{5}$. Os pacientes só podem participar de pesquisas terapêuticas se elas forem benéficas, o que pode incluir testes de drogas psiquiátricas, terapias comportamentais ou intervenções cirúrgicas.

Já as pesquisas não terapêuticas são as envolvidas na fase I do estágio do estudo clínico, como testes para desenvolvimento de vacinas, de novos medicamentos para avaliar riscos e efeitos colaterais. A distinção entre pesquisas terapêuticas e não terapêuticas é pertinente, mas pode levar ao equívoco de que as terapêuticas são menos danosas e mais benéficas. Isso não é verdadeiro, já que drogas novas para doentes mentais não estão isentas de risco.

\section{O uso e abuso de psicofármacos e as pesquisas com placebo}

Os transtornos mentais nunca deixarão de existir. Novas patologias foram categorizadas de 1952 para cá. Passou-se de 106 tipos na década de 1950 para 292 no século XXI. Já em 1994, se dizia que o crescente número de "novas patologias" reflete os vários e, frequentemente, contraditórios valores e crenças presentes na sociedade afetando as pessoas e suas famílias ${ }^{41}$.

Eis um caso exemplar: um pesquisador brasileiro ${ }^{35}$ que defende o uso de placebo com novas drogas critica a Declaração de Helsinki, quando determina que novos métodos devam ser comparados somente com os melhores existentes, evitando-se o placebo. Se obedecido literalmente esse item inviabilizaria os estudos placebos-controlados fundamentais para a determinação da eficácia de psicofármacos ${ }^{35}$. Seus argumentos são: o estudo com placebo é essencial para comprovar a eficácia de tratamentos em razão das características da doença mental como a "heterogeneidade clínica, cronicidade e evolução muito variável”, que explicam, em parte, o fato de o placebo "induzir" alto grau de melhora de pacientes com diferentes condições psiquiátricas. O autor cita desde quadros de profunda depressão endógena, psicótica ou o estupor depressivo até uma garota que terminou um namoro e há duas semanas está com leve tristeza, um pouco de insônia, ligeira diminuição da capacidade de concentração e menos apetite ${ }^{35}$. Segundo ele, a resposta ao placebo é alta e varia entre $30 \%$ e $70 \%$ dos casos de pessoas com diferentes transtornos mentais, inclusive os mais graves, como a mania, e é exigido pelos periódicos internacionais, agências reguladoras de vários países e pela comunidade científica internacional. Diz o autor: o placebo é muito mais do que uma simples cápsula de farinha [e implica] uma intervenção terapêutica considerável. [...] Seis sessões de aconselhamento foram tão eficazes quanto medicamentos antidepressivos no tratamento da depressão maior e em um ensaio clínico complexo [...] os pacientes recebem graus de atenção que facilmente podem ser comparados a seis sessões de aconselhamento em pacientes com uso de placebo, quando comparados a outros: a melhora nos grupos-controle com placebo foi significativamente maior do que os das listas de espera [das clínicas de terapia cognitivo-comportamental] e quase tão grande quanto a obtida com os medicamentos antidepressivos $^{35}$. Assim, as comparações dos efeitos terapêuticos de medicamentos ou de psicoterapias, novos ou antigos, sem o grupo-controle com placebo não permitem conclusões sobre a eficácia dos tratamentos porque a "melhora" observada pode ser causada por fatores inespecíficos ${ }^{35}$. Em suma, nos transtornos mentais, como o bipolar, os tratamentos disponíveis "estão muito longe" de produzir resultados satisfatórios, pois estudos bem feitos e amplos mostrariam que cerca de $50 \%$ dos pacientes bipolares pioram, e [n] a gênese desse péssimo estado de coisas existe, inclusive, a hipótese [...] de que o uso excessivo de medicamentos insatisfatórios estaria piorando os quadros clínicos, em médio e longo prazo ${ }^{35}$. Dentre os problemas desse raciocínio, o autor só apresentou casos de pesquisas sobre depressões, da mais leve à mais pro- 
funda, o que é problemático por elas terem causalidades diferentes. De fato, seu artigo não exemplifica casos de esquizofrenia, em que, segundo vários autores, os pacientes não são suscetíveis de melhoria dos sintomas com psicoterapias ${ }^{42}$.

Do artigo citado se infere que, se o paciente fosse tratado com escuta a suas necessidades, estar-se-ia impedindo que medicamentos fossem patenteados e utilizados. Nesse sentido, o placebo (e as drogas?) serviria também para provar que melhoras são possíveis por fatores inespecíficos. Entretanto, fica sempre uma sensação desconfortável em relação à pesquisa em saúde mental: se os pacientes melhoram com sessões de aconselhamento, ou por serem examinados, perguntados e ouvidos, em razão de uma pesquisa, por que isso não acontece no dia a dia dos ambulatórios ou hospitais?

\section{Considerações finais}

Este artigo induz à necessidade de se ampliar a discussão sobre o TCLE na psiquiatria: em geral, os médicos e os psiquiatras ignoram os estudos de mais de quarenta anos sobre esse tema por parte da bioética.

Posições antagônicas indicam que o campo da saúde mental, especialmente o das investigações, está minado por vieses. Não se pode, entretanto, deixar de reconhecer as dificuldades quase intransponíveis de se fazerem investigações que contribuam para a cura das pessoas com transtornos mentais. Fica claro que, apesar da intenção de defendê-las, as regulamentações internacionais e nacionais não as protegem eficazmente. Nesse sentido, deve-se atentar para as mudanças que vêm ocorrendo em razão da Reforma Psiquiátrica no Brasil, o que vem contribuindo para transformar concepções obsoletas sobre a doença mental e os afetados por ela.

A questão do necessário consentimento ligado à autonomia desse grupo, se não for plenamente respeitada, acaba por ser um instrumento de risco e vulnerabilidade. No entanto, observase que a substituição do consentimento livre e esclarecido em primeira pessoa pode servir mais prontamente aos interesses dos pesquisadores do que aos interesses dos participantes da pesquisa, pois [a] figura do consentimento dado por meio de uma procuração não pode substituir o consentimento livre e esclarecido em primeira pessoa e precauções especiais devem ser tomadas em relação às pesquisas envolvendo indivíduos mentalmente incapazes.

O consentimento deve ser solicitado nos períodos em que os pacientes estejam fora de crises, embora alguns considerem que a ética do paciente psiquiátrico não deve estar subordinada ao que se entende por autonomia em bioética. Pela natureza controversa de muitos aspectos das bases conceituais da psiquiatria, a ética psiquiátrica tem sido julgada como "o patinho feio da ética biomédica" ${ }^{20}$.

Há também a questão do status epistemológico dos conceitos, diagnósticos e categorias, pois os grandes distúrbios mais bem descritos ainda não possuem base científica totalmente conhecida. Assim, para muitos, ainda é melhor calar o sujeito com medicação e, assim, tranquilizar a sociedade, mesmo que a cronicidade não desapareça.

É necessário ter coragem para mudar, pois é inadmissivel que a Psiquiatria seja utilizada para cercear a liberdade, restringir direitos, oprimir cidadãos ${ }^{43}$.

\section{Colaboradores}

M Braz foi responsável pela concepção, pelo levantamento bibliográfico e redação do artigo; FR Schramm participou da discussão e da revisão final. 


\section{Referências}

1. Foucault M. História da loucura. São Paulo: Perspectiva; 1987.

2. Foucault M. Doença mental e psicologia. Rio de Janeiro: Tempo Brasileiro; 1975.

3. Zilboorg G, Henri G. Historia de La Psicologia Médica. Buenos Aires: Hachette; 1945.

4. Frota LH. Cinqüenta anos de medicamentos antipsicóticos em psiquiatria. [documento na Internet]. 2003 [acessado 2011 fev 10]; [cerca de 486 p.]. Disponível em: http://www.medicina.ufrj.br/cursos/LH\%20 FROTA $\% 20-\% 201 \% 20$ Ed $\% 20-2050 \% 20$ ANOS $\% 20$ DE\%20MEDICAMENTOS\%20ANTIPSICOTICOS. pdf

5. Lott J. Populações especiais e vulneráveis. In: Diniz D, Guilhem D, Schüklenk U, editores. Ética em pesquisa: experiência de treinamento em países sul-africanos. Brasília: Letras Livres/UnB; 2005. p. 70-102. [livro na Internet]. 2005 [acessado 2011 jan 12]; [cerca de 4 p.]. Disponível em: http://www.udoschuklenk.org/files/modulo3.pdf

6. Riof M. Vulnerabilty, vulnerable populations and policy. Scope Note 44. Geneve: CIOM, WHO, The Joseph and Rose Kennedy Institute of Ethics; 2002.

7. Ayres JRCM, Júnior F, Calazans I, Filho GJS, César H. O conceito de vulnerabilidade e as práticas de saúde: novas perspectivas e desafios. In: Czeresnia D, Freitas CM, organizadores. Promoção da saúde: conceitos, reflexões, tendências. Rio de Janeiro: Editora Fiocruz; 2003. p. 117-139.

8. Mann J, Tarantola DJM, Netter T. A Aids no mundo. Rio de Janeiro: Relume-Dumará, IMS, Uerj; 1993.

9. Braz M. Vulnerabilidad y autonomia: el sujeto de la investigación en los países en desarrollo. In: Hoof PF, Chaparro E, Salvador H, compiladores. Bioética, vulnerabilidad y educación. v. 2. Mar del Plata: Suaréz; 2003. p. 79-94.

10. Giffoni D, Braz M. Vulnerabilidade, autonomia e ética em pesquisa. Revista Brasileira de Bioética 2008; 4(1,2):49-68.

11. Kottow M. Autonomía y protección en bioética. Jurisprudência Argentina (JA) 2005; III(13):44-49.

12. Schramm, FR, Braz M. Bioethics of protection: a proposal for the moral problems of developing countries? J Int Bioethique 2008; 19(1-2):73-86.

13. Código de Nuremberg. Tribunal Internacional de Nuremberg - 1947. Trials of war criminal before the Nuremberg Military Tribunals. Control Council Law [periódico na Internet] 1949; 10(2):181-182. [periódico na Internet]. [acessado 2011 jan 03]; [cerca de 1 p.]. Disponível em: http://www.ufrgs.br/ bioetica/nuremcod.htm

14. Declaração de Helsinki I. Adotada na $18^{\text {a }}$ Assembléia Médica Mundial, Helsinki, Finlândia,1964. [documento na Internet]. 1964 [acessado 2011 jan 11]. Disponível em: http://www.ufrgs.br/bioetica/ helsin $1 . h$ tm

15. Declaração de Helsinki V.48a. Sommerset West/África do Sul, 1996 [acessado 2011 jan 02] 1996 [cerca de 2 p.]. Disponível em: http://www.bioetica.ufrgs. br/helsin5.htm
16. Lurie P, Wolfe S. Unethical trials of interventions to reduce perinatal transmission of the human immunodeficiency virus in developing countries. $N$ Engl J Med 1997; 337:853-856.

17. Declaração de Helsinki. 52 nd WMA General Assembly, Edinburgh, Scotland, October 2000. [documento na Internet]. 2000 [acessado $2010 \mathrm{dez}$ 16]; [cerca de 2 p.]. Disponível em: http://www.bioetica.ufrgs.br/ helsin6.pdf

18. World Medical Association (WMA). Declaration of Helsinki. Ethical Principles for Medical Research Involving Human Subjects. 59th WMA General Assembly, Seoul, October 2008. [documento na Internet]. 2008 [acessado $2010 \mathrm{dez} 7$ ]; [cerca de 2 p.]. Disponível em: http://www.ufrgs.br/bioetica/helsin7.pdf

19. Garrafa V, Lorenzo C. Helsinque 2008: redução de proteção e maximização de interesses privados. Rev Assoc Med Bras 2009; 55(5):514-518.

20. Radden J. Psychiatric ethics. Bioethics 2002; 16(5): 397-411.

21. Beauchamp TL, Childress JF. Princípios da ética biomédica. São Paulo: Loyola; 2002.

22. Miranda AJA. Bioética e saúde mental no limiar dos limites: o que o doente mental mantém de homem ético [dissertação]. Porto: Faculdade de Medicina da Universidade do Porto; 2008. [documento na Internet]. 2008 [acessado $2010 \mathrm{dez} 11$ ]. Disponível em: http://repositorio-aberto.up.pt/bitstream/10216/ 22144/3/Biotica\%20e\%20Sade\%20Mental.pdf

23. The Disability Rights California. Personal Autonomy Principles. [documento na Internet]. 2007 [acessado $2010 \mathrm{dez} 8$ ]; [cerca de 4 p.]. Disponível em: http://www.disabilityrightsca.org/legislature/ Principles/102401.htm

24. Zanerato E. Marcha em Brasília pede inserção de doentes mentais na sociedade. [documento na Internet]. 2009 [acessado 2011 jan 2]; [cerca de 1 p.]. Disponível em: http://www.vermelho.org.br/noticia.php?id_ noticia $=116668 \&$ \&id secao $=8$

25. Código de Ética Médica. Resolução CFM n $1.931 /$ 2009. Em vigor em abril de 2010. [documento na Internet]. 2010 [acessado 2010 maio 9]. Disponível em: http://www.portalmedico.org.br/novocodigo/ integra.asp

26. Fry ST. Ética na prática da enfermagem comunitária. In: Stanhope M, Lancaster J, organizadores. Enfermagem comunitária: promoção da saúde de grupos, famílias e indivíduos. Lisboa: Lusociência; 1999. p. 101-126.

27. Bonta J, Law M, Hanson K. The prediction of criminal and violent recidivism among mentally disordered offenders: a meta-analysis. Psycholocal Bulletin 1998; 123:123-142.

28. Steinert T. Reducing violence in severe mental illness: community care does not do well. BMJ [editorial]. 2001; 323:1093.

29. Manzini JL. Las directivas anticipadas para tratamientos médicos. Jurisprudencia Argentina (JA) 2001; 4(11):40-47. 
30. Brasil. Ministério da Saúde. Conselho Nacional de Saúde. Resolução CNS no 196/96: diretrizes e normas regulamentadoras de pesquisas envolvendo seres $h u-$ manos, 1996. [documento na Internet]. 1996 [acessado 2011 jan 7]. Disponível em: http://www.ufrgs.br/ bioetica/res19696.htm

31. Fazenda I. Empowerment e participação, uma estratégia de mudança. Centro Português de Investigação e História e Trabalho Social. [documento na Internet]. [acessado 2011 jan 23]. [cerca de 1 p.]. Disponível em: http://www.cpihts.com/pdf/empowerment.pdf

32. Geraldes PC. A autonomia na doença mental. Jornal da Cremerj. [documento na Internet] [acessado 2011 jan 2]. Disponível em: http://www.cremerj.org.br/ jornais/mostraMateria.php?idJornal=24\&idMateria $=235$

33. Zaubler TS, Viederman M, Fins JJ. Ethical, legal and psychiatric issues in capacity, competency and informed consent: an annotated bibliography. Gen Hosp Psychiatry 1996; 18:155-172.

34. Schüklenk U. Protecting the vulnerable: testing times for clinical research ethics. Social Science and Medicine 2000; 51:969-977.

35. Versiani M. A necessidade do grupo-controle com placebo em pesquisas sobre a eficiência de tratamentos psiquiátricos. Bioética 2000; 8(1):29-42.

36. Fé IAM. Bioética, doença mental e autonomia. Bioética 1998; 6(1):71-79.

37. Roth LH, Meisel A, Lidz CW. Tests of compe- tency to consent to treatment. Am J Psychiatry 1977; 134: 279-284.

38. Lopes MHI. Pesquisa em hospitais psiquiátricos. Porto Alegre. [documento na Internet]. [acessado 2011 fev 10]; [cerca de 5 p.]. Disponível em: http:// www.ufrgs.br/bioetica/psiqpes.htm

39. Irwin M, Lovitz A, Marder SR, Mintz J, Winslade WJ, Van Putten T. Psychotic patients understanding of informed consent. Am J Psychiatry 1985; 142:1351-1354.

40. Hossne WS. O poder e as injustiças nas pesquisas. Comunic, Saúde, Educ 2003; 7(12):55-70.

41. Webb-Mitchell B. Disability: philosophical and theological perspctives. In: Reich WT, editor. Encyclopedia of bioethics. New York: Library of Congress Catalog-in-Publication; 1995.

42. Shirakawa I. Psicanálise na esquizofrenia. Rev Bras Psiquiatr 2011; 22(3):47-148.

43. Jorge MR, França JMF. A Associação Brasileira de Psiquiatria e a reforma da assistência psiquiátrica no Brasil. Rev Bras Psiquiatr 2001; 23(1):3-6. 